\title{
Improving the efficiency of energy complexes and heat supply systems using mathematical modeling methods at the operational stage
}

\author{
$S O$ Gaponenko*, $A$ E Kondratiev and $R Z$ Shakurova \\ Industrial heat power engineering and heat supply systems department, Kazan State Power Engineering University, 51 Krasnoselskaya \\ str., Kazan, 420066, Russia
}

\begin{abstract}
Improving the efficiency and energy saving of energy complexes and heat supply systems is one the most important fields of the Russian economy modernization. In the field of industrial heat and power engineering, the increasing energy efficiency is an urgent task both at the design stage and at the equipment operation stage. For these purposes, numerical modeling methods are actively used. The paper presents the developed mathematical model of the pipeline located in the soil, which allows improving efficiency of energy systems and heat supply systems at the stage of operation. Also this paper presents the results of laboratory studies, namely, the informative frequency ranges of the investigated pipeline for further assessment of its technical condition.
\end{abstract}

\section{Introduction}

Improving the efficiency and energy saving of energy complexes and heat supply systems is one of the most important fields of the Russian economy modernization. In the adopted Energy Strategy of Russia for the period up to 2035, as well as in the Federal Law No. 190-FZ "On Heat Supply ...", one of the development priorities of the energy industry is to increase the reliability of heat supply, as well as to reduce heat losses during transportation of coolant. Recently, due to deterioration of heating systems, much attention has been paid to improving the energy security of the citizens' heat supply. In the field of industrial heat and power engineering, increasing energy efficiency is an urgent task, both at the design stage when making decisions and at the equipment operation stage. For these purposes, mathematical modeling is actively used. Mathematical models of processes are built on the basis of solving systems of differential and sometimes integrodifferential equations. To solve such systems, numerical methods are mainly used.

Recently, multiphysical numerical software packages, such as ANSYS, FlowVision, Phoenics, etc., are increasingly being used to simulate heat technology and power plants. In this work, the ANSYS software package is used.

The use of mathematical modeling methods will improve the accuracy of diagnosing energy complexes and heat supply systems, for example, pipeline systems, which in turn will lead to increased reliability and energy efficiency, including reduced costs for eliminating accidents and energy losses, and saving primary energy resources.
Direct spectral problems on oscillations of mechanical systems are considered in many works on the theory of oscillations, including that of I.I. Artobolevsky, I.M. Babakov, I.I. Blekhman, V.V. Bolotin, S.P. Strelkov, S.P. Tymoshenko [1-2]. The study of inverse spectral problems originates in the fundamental works of V.A. Amburtsumyan and G. Borg. A significant contribution to the formation of this direction was made by the works of A.N. Tikhonov, B.M. Levitan, V.A. Marchenko, M.G. Gasymova, V.A. Yurko, G.M.L. Gladwell and others [3-4].

In heat supply systems constructions in the form of shell are widely used, their natural frequencies and corresponding forms of vibration are determined. The tasks of acoustic diagnostics of mechanical systems, which also include constructions in the form of shells, are considered in a great number of works, including the works [1-7]. Earlier in the works [8-21], the increase in the efficiency of energy complexes and heat supply systems was studied using the methods of mathematical modeling by the natural frequencies of their oscillations.

\section{Calculation of the frequency characteristics of the pipeline under the soil pressure}

Before the pipeline is laid into the soil, soil in an unlimited array is in a state of natural or geostatic equilibrium under its own weight. At the same time, compressive stresses (pressures) act on the depth $H$ in the soil massif (figure 1): vertical pressure $q_{v}$ and horizontal pressure $q_{h}$ [22].

* Corresponding author: sogaponenko@yandex.ru 


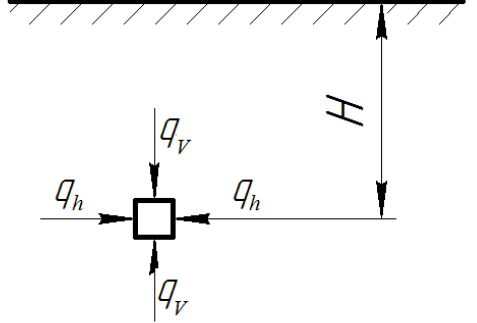

Fig. 1. A pipeline in the soil.

The soil pressure on the underground pipeline turns out to be different from the pressure in an intact massif at the same depth, which can be explained by a number of reasons: firstly, the pipeline has a different stiffness than the ground; secondly, there exist a soil movement time occurring in the period between the ground scraping and the construction of pipeline; and finally, gaps remain between the pipeline and the massifs, which allow some movement of the ground [22].

The pressure exerted by the soil on the pipeline depends on the depth and rigidity of the pipeline, moisture and degree of soil compaction over the pipeline, and especially next to it, and also pressure depends on the pipeline construction method. There are three main cases of pipeline construction, namely:

- Pipeline in the embankment (figure 2, a), erected or laid directly on the earth surface or laid in a very small recess compared to the width of the recess followed by backfilling. This is a common way for culverts construction under the road embankments;

- Pipeline in the excavation or in the trench (figure 2, b), which is built or stacked in an open excavation, having a small width compared to its depth and is limited by more or less solid walls; the space near the pipeline and above it is filled with soil. Water pipes, sewers, gutters, etc. are usually laid in this way;

- Pipeline erected in a closed way (figure 2, c), in this case, the massif of soil is not disturbed from the surface, this method is used in the construction of tunnels and in trenchless laying of pipelines [22].

The soil pressure on the underground pipeline does not remain constant, but changes due to changes in temperature and humidity conditions and creep of the soil. In most cases, the pressure on the structure gradually increases over time, reaching the maximum value after a certain period, sometimes followed by decreasing. Underground pipelines are considered either as an elastic or as a flowing medium to determine the pressure of the soil on them. [22].

The resultant of the calculated vertical load from the pressure of the soil backfill when laying pipelines is determined by the formulas:

- When laying the pipeline in the trench (1):

$$
\mathrm{Q}_{\mathrm{T}}=\mathrm{n} \gamma \mathrm{HBK}_{\mathrm{TR}} \psi
$$

When laying the pipeline in the mound (2):

$$
\mathrm{Q}_{\mathrm{M}}=\mathrm{n} \gamma \mathrm{HD}_{\mathrm{M}} \mathrm{K}_{\mathrm{M}}
$$

The smaller of the calculated values is taken as $Q$.

If in formula (1) the product $\mathrm{BK}_{\mathrm{TR}}$ turns out to be greater than the product $\mathrm{D}_{M} \mathrm{~K}_{\mathrm{M}}$ in formula (2) defined for the same base soil and pipeline construction methods, therefore, when laying pipes in a trench one should use formula (2) instead of formula (1).

The overload coefficients $n$ for external permanent and temporary loads are taken according to table 1 [22].

Table 1. Overload Rate.

\begin{tabular}{|l|c|}
\hline \multicolumn{1}{|c|}{ Loads } & $\begin{array}{c}\text { Overload } \\
\text { coefficient } \boldsymbol{n}\end{array}$ \\
\hline 1. Soil vertical pressure & 1.15 \\
\hline 2. Horizontal ground pressure & 0.8 \\
\hline 3. Vertical transport pressure for & \\
schemes: & \\
A-14 & 1.4 \\
NG-60, NK-80 & 1.1 \\
\hline 4. Horizontal transport pressure & 1.0 \\
\hline 5. Pipeline own weight & 1.1 \\
\hline 6. Bulk weight & 1.0 \\
\hline
\end{tabular}

Backfill soils are divided into six categories. The normative values of the specific weight $\gamma$ and modulus of deformation $\mathrm{E}_{\mathrm{s}}$ for soil backfill are shown in table 2 [22]. a)

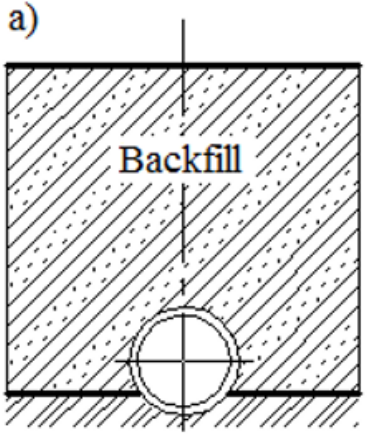

Natural soil b)

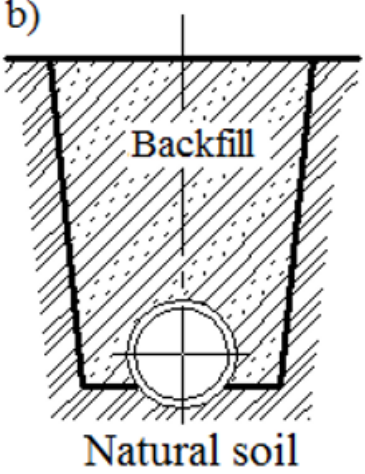

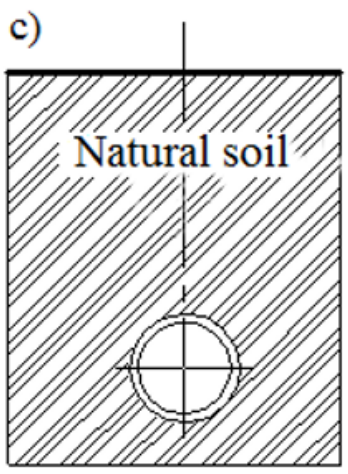

Fig. 2. Methods for pipeline construction in the soil. 
Table 2. Normative values.

\begin{tabular}{|c|c|c|c|c|}
\hline \multirow{2}{*}{ Soil category } & Soil type & $\begin{array}{c}\text { Ground } \\
\text { weight, } \mathrm{kN} / \mathrm{m}^{3}\end{array}$ & $\begin{array}{c}\text { Normative values of the modulus of } \\
\text { deformation of the soil backfill Es, MPa, } \\
\text { with the degree of compaction }\end{array}$ \\
\cline { 3 - 5 } & & & 7.0 & Normative \\
\hline G-I & $\begin{array}{c}\text { Gravel, coarse and } \\
\text { medium sands }\end{array}$ & 16.7 & 3.9 & 14.0 \\
\hline G-II & Fine sands & 16.7 & 2.2 & 4.4 \\
\hline G-III & Dusty sands & 17.7 & 1.2 & 2.4 \\
\hline G-IV & Clay & 18.6 & 1.1 & 2.2 \\
\hline G-V & Loam & 18.6 & 1 & 2.0 \\
\hline G-VI & Heavy clay & 19.0 & \\
\hline
\end{tabular}

Table 3. Calculated values of pressure of different types of soil depending on the depth.

\begin{tabular}{|l|c|l|l|l|c|}
\hline $\begin{array}{c}\text { Soil } \\
\text { type }\end{array}$ & $\begin{array}{l}\text { Pressure, } \mathrm{kN} / \mathrm{m}^{2} \\
(\text { depth } 0.7 \mathrm{~m})\end{array}$ & $\begin{array}{l}\text { Pressure, } \\
\mathrm{kN} / \mathrm{m}^{2} \\
\text { (depth } 1 \mathrm{~m})\end{array}$ & $\begin{array}{l}\text { Pressure, } \\
\mathrm{kN} / \mathrm{m}^{2} \\
\text { (depth } 1.3 \mathrm{~m})\end{array}$ & $\begin{array}{l}\text { Pressure, } \\
\mathrm{kN} / \mathrm{m}^{2} \\
(\text { depth } 2 \mathrm{~m})\end{array}$ & $\begin{array}{l}\text { Pressure, } \mathrm{kN} / \mathrm{m}^{2} \\
(\text { depth 2.5 m) }\end{array}$ \\
\hline Fine sands & 27.418 & 39.243 & 51.068 & 78.659 & 98.366 \\
\hline Dusty sands & 29.063 & 41.597 & 54.131 & 83.378 & 104.268 \\
\hline Clay & 30.543 & 43.715 & 56.889 & 87.623 & 109.578 \\
\hline Loam & 30.49 & 43.7 & 56.888 & 87.624 & 109.57 \\
\hline Heavy clay & 31.2 & 44.66 & 58.112 & 89.509 & 111.935 \\
\hline
\end{tabular}

The trench width $B$ is determined by the project and depends on the size of the working bodies of the earthmoving equipment.

In accordance with SP 66.13330.2011 [22], the smallest trench width along the bottom should be $\mathrm{D}_{\mathrm{M}}+$ $600 \mathrm{~mm}$. Trench width $B$ at the top of pipes are presented in figure 3 .
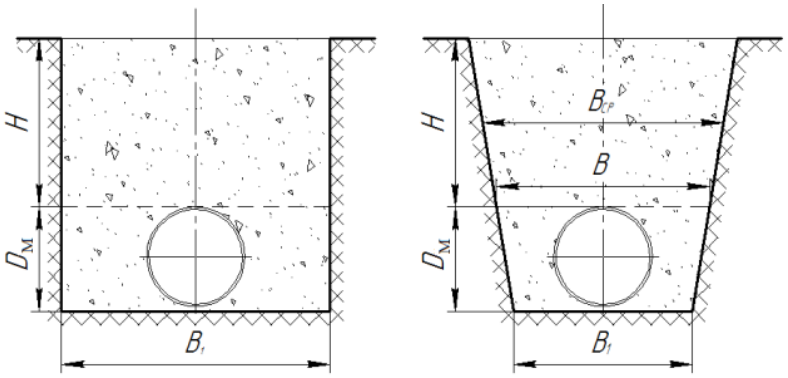

Fig. 3. Schemes of laying underground pipeline.

A mathematical model is formulated to increase the efficiency of the heat supply system according to the reliability criterion. Models of pipelines of various geometrical sizes and materials were built using the ANSYS software package [8-21]. Various pipeline depths and soil nature were simulated by changing the pressure on its walls (table 3 ).

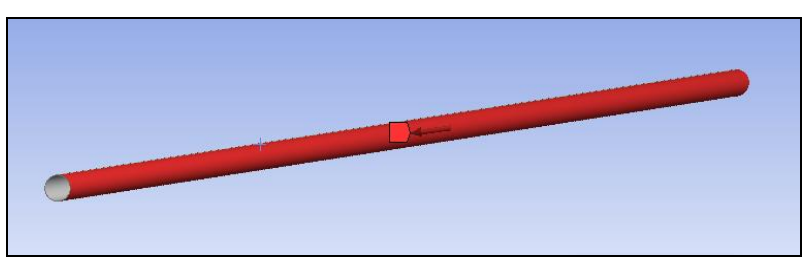

Fig. 4. The pipeline model with applied pressure.

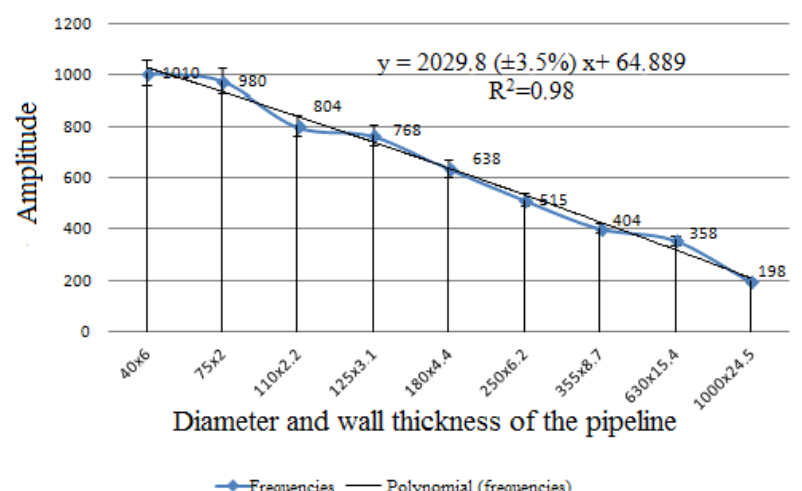

Fig. 5. Informative frequency ranges for monitoring the location of buried pipelines. 
Table 4. Calculation results.

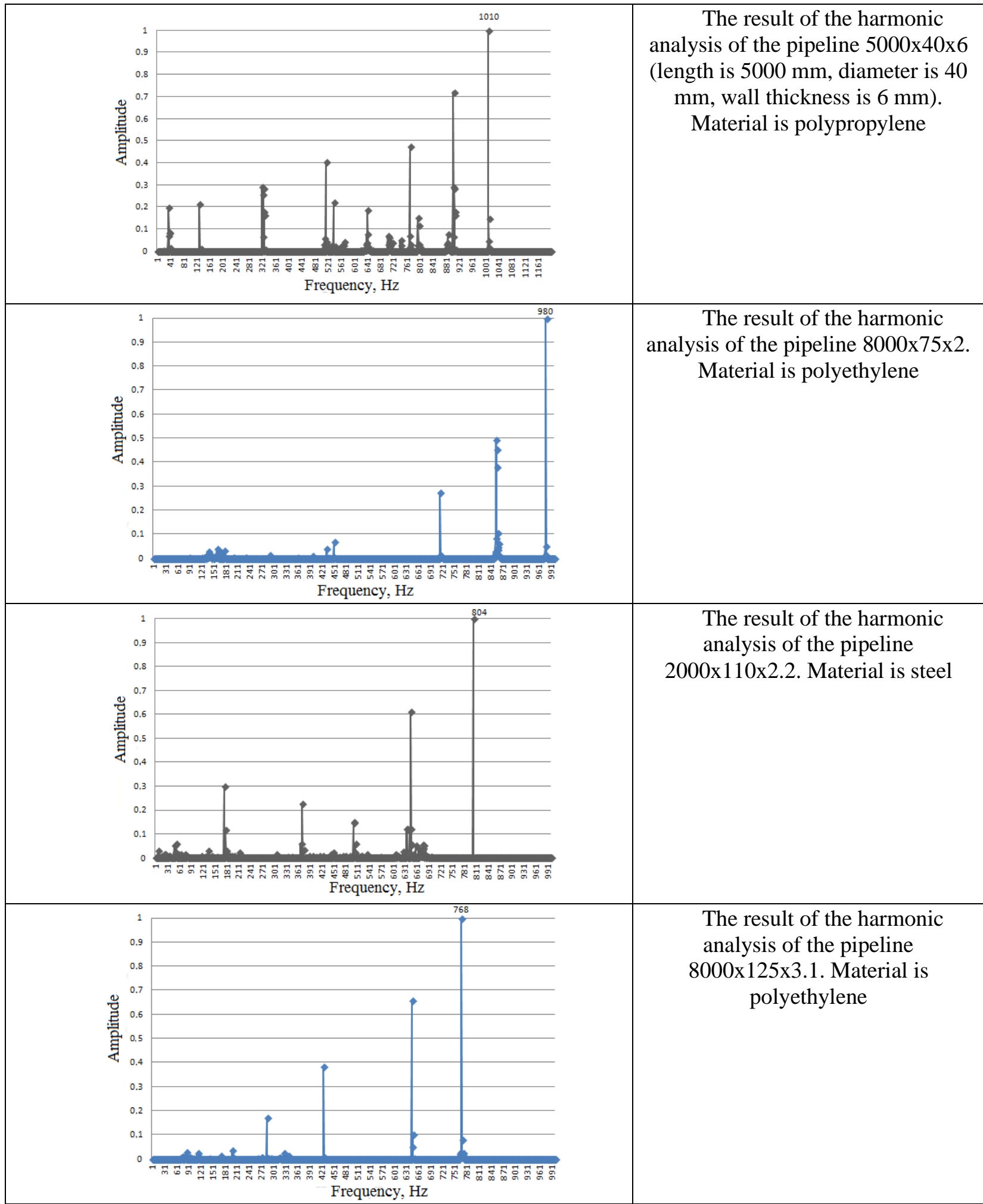

\section{Conclusion}

The studies presented in this paper allowed us to formulate the following conclusions:
1. The informative frequency ranges of monitoring the location of buried pipelines made of different materials are determined.

2. Variations in soil type, depth, material and length of the pipeline do not affect the selected resonant oscillation frequencies. 
Table 5. Calculation results.

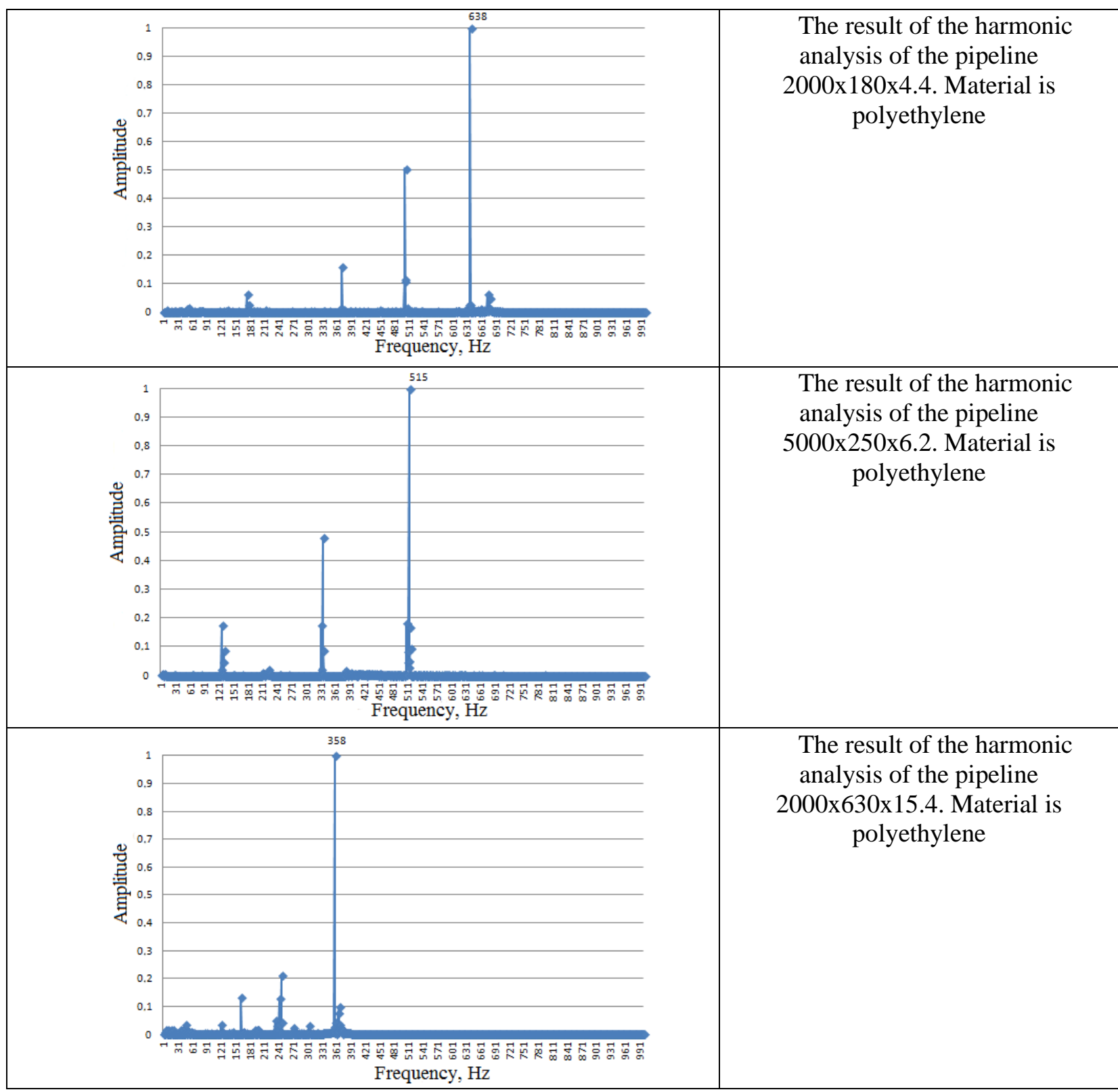

3. The selected resonant frequencies depend almost linearly on the diameter of the pipeline under study.

4. The most informative frequency range is $100-$ $1100 \mathrm{~Hz}$, in which the selected resonant frequencies of the simulated pipelines are located (Fig. 3).

Consequently, the fundamental harmonic depends on the diameter of the pipeline.

\section{References}

1. I.M. Babakov, Teoriya kolebanij [Oscillation theory], 593 (2004)

2. S.P. Timoshenko, Fluctuations in engineering, 440 (1959)

3. V.A. Yurko, Introduction to the theory of inverse spectral problems, 384 (2007)
4. G.M.L. Gladwell, Inverse Problems in Vibration, 2 (2004)

5. V.A. Bruyaka, V.G. Fokin, E.A. Soldusova, N.A. Glazunova, I.E. Adeyanov, Engineering Analysis at ANSYS Workbench, 271 (2010)

6. A. Shirman, A. Soloviev, Practical vibration diagnostics and monitoring of mechanical equipment, 276 (1996)

7. N.V. Leontiev, Application of the ANSYS system to solving modal and harmonic analysis problems (2006)

8. S.O. Gaponenko, Acoustic-resonant informationmeasuring complex and methods for monitoring the location of buried pipelines, Extended Abstract of Cand., 22 (2017)

9. S.O. Gaponenko, A.E. Kondratiev, Model plant for developing a method for determining the location of hidden pipelines, Izvestiya vysshih uchebnyh zavedenij. Problemy energetiki, 7-8, 123-129 (2014) 
10. S.O. Gaponenko, A.E. Kondratiev, Prospective methods and techniques for finding hidden channels, cavities and pipelines by the vibro-acoustic method, Vestnik Severo-Kavkazskogo federal'nogo universiteta, 2(47), 9-13 (2015)

11. S.O. Gaponenko, A.E. Kondratiev, Measuring and diagnostic complex to determine the location of hidden pipelines, Izvestiya vysshih uchebnyh zavedenij. Problemy energetiki, 3-4, 138-141 (2013)

12. S.O. Gaponenko, A.E. Kondratiev, A.R. Zagretdinov, Low-frequency vibro-acoustic method of determination of the location of the hidden canals and pipelines, Procedia Engineering, 150, 2321-2326 (2016) 13. S.A. Nazarychev, S.O. Gaponenko, A.E. Kondratiev, Determination of informative frequency ranges for buried pipeline location control, Helix, 8(1), 2481-2487 (2018)

14. S.O. Gaponenko, A.E. Kondratiev, A.R. Zagretdinov, Method for determining the trace of hidden pipelines, Scientific progress - the creativity of young, 24, 163-165 (2016)

15. S.O. Gaponenko, The method of determining the location of the pipeline, Patent RF, 2482515 (2013)

16. S.O. Gaponenko, A.E. Kondratiev, Universal method for determining the trace of hidden pipelines, XXII International Youth Scientific Conference "Tinchurin Readings", 2, 74-76 (2017)

17. S.O. Gaponenko, A.E. Kondratiev, Technique for finding hidden hollow objects in the ground, Scientific progress - the creativity of young, 2-4, 115-118 (2017)

18. S.O. Gaponenko, Application of new methods for detecting buried hollow objects, 570-575 (2016)

19. S.O. Gaponenko, A.E. Kondratiev, Methods for controlling the location of buried pipelines, XIII International Youth Scientific Conference "Tinchurin Readings", 157-160, (2018)

20. S.O. Gaponenko, A.E. Kondratiev, A.A. Ibadov, A.F. Nigmatullina, Mathematical modeling of oscillations of an elastic shell under external influence on the example of a pipeline, IX International Youth Scientific and Technical Conference "Electric Power Industry through the Eyes of Youth - 2018", 265-268 (2018)

21. S.O. Gaponenko, A.E. Kondratiev, A.A. Ibadov, Determination of informative frequency ranges for monitoring the location of buried pipelines, Scientific progress - the creativity of young, 2, 68-71 (2018)

22. Set of Rules 66.13330.2011. Design and construction of pressure water supply and drainage networks using high-strength nodular cast iron pipes, Standartinform Publ., 116 (2011) 